\title{
Cyclin-dependent kinases 7 and 9 specifically regulate neutrophil transcription and their inhibition drives apoptosis to promote resolution of inflammation
}

\author{
AE Leitch ${ }^{1}$, CD Lucas ${ }^{1}$, JA Marwick ${ }^{1}$, R Duffin ${ }^{1}$, C Haslett ${ }^{1}$ and AG Rossi ${ }^{\star *,}$
}

Terminally differentiated neutrophils are short-lived but the key effector cells of the innate immune response, and have a prominent role in the pathogenesis and propagation of many inflammatory diseases. Delayed apoptosis, which is responsible for their extended longevity, is critically dependent on a balance of intracellular survival versus pro-apoptotic proteins. Here, we elucidate the mechanism by which the cyclin-dependent kinase (CDK) inhibitor drugs such as R-roscovitine and DRB (5,6-dichloro-1-beta-D-ribofuranosylbenzimidazole) mediate neutrophil apoptosis. We demonstrate (by a combination of microarray, confocal microscopy, apoptosis assays and western blotting) that the phosphorylation of RNA polymerase II by CDKs 7 and 9 is inhibited by R-roscovitine and that specific effects on neutrophil transcriptional capacity are responsible for neutrophil apoptosis. Finally, we show that specific CDK7 and 9 inhibition with DRB drives resolution of neutrophil-dominant inflammation. Thus, we highlight a novel mechanism that controls both primary human neutrophil transcription and apoptosis that could be targeted by selective CDK inhibitor drugs to resolve established inflammation.

Cell Death and Differentiation (2012) 19, 1950-1961; doi:10.1038/cdd.2012.80; published online 29 June 2012

Granulocyte apoptosis and their removal by phagocytes, particularly macrophages, is essential for resolution of inflammation. ${ }^{1,2}$ The neutrophil, which although short-lived in the circulation, is granted an extended life span by survival signals at inflammatory sites. ${ }^{3}$ Apoptosis renders these potentially histotoxic cells functionally redundant ${ }^{4}$ and ensures their recognition and clearance by macrophages. ${ }^{2}$ If this process is uncontrolled, then non-resolving chronic inflammation results. Neutrophils that are over-activated or undergo necrosis release their toxic granule contents, causing unwanted tissue damage. By inducing neutrophil apoptosis together with efficient macrophage removal, it is possible to promote the resolution of inflammation. ${ }^{5}$ Indeed, delivery of apoptotic cells protects mice from endotoxin-induced shock, ${ }^{5}$ highlighting a potential therapeutic role for inducing early apoptosis. Further approaches with equal translational promise include the use of cyclin-dependent kinase (CDK) inhibitor drugs, ${ }^{6}$ aspirin-triggered 15 -epi-LXA ${ }^{8}$ and TRAIL (via specific death receptor signalling). ${ }^{7,8}$

To drive neutrophil apoptosis, it is important to understand the mechanisms responsible for neutrophil survival. A key neutrophil survival protein is $\mathrm{Mcl}-1$ as demonstrated by studies using anti-sense Mcl-1 RNA to 'knockdown' Mcl-1 and $\mathrm{Mcl}-1$ myeloid-specific knockout mice. ${ }^{9,10} \mathrm{Mcl}-1$ confers a pro-survival effect by an interaction with pro-apoptotic Bcl-2 homologues (Bid, Bax, Bak) that prevents their association with the outer mitochondrial membrane and its subsequent permeabilisation thereby avoiding progression down the intrinsic apoptotic pathway. ${ }^{11}$ An important pro-apoptotic $\mathrm{Bcl}-2$ homologue responsible for regulation of neutrophil apoptosis, especially in the context of inflammation and cytokine-mediated extended longevity, is Bim. ${ }^{12}$ We have shown that although $\mathrm{Mcl}-1$ is downregulated at the level of transcription by the CDK inhibitor R-roscovitine protein levels of Bim are maintained. ${ }^{13} \mathrm{Mcl}-1$ is an unusually large $\mathrm{Bcl}-2$ homologue because it contains PEST domains in its C-terminal tail that target it for degradation by the proteasome ${ }^{11}$ Rapid up or downregulation of transcription, a short half-life and extensive regulation, make $\mathrm{Mcl}-1$ an ideal 'survival switch' for regulating neutrophil apoptosis. Not only survival signals (e.g., GM-CSF) but also pharmacological agents (e.g., dexamethasone ${ }^{15}$ and sodium salicylate ${ }^{16}$ ) can alter Mcl-1 half-life and neutrophil survival, but there is still a niche for agents capable of driving resolution of inflammation. Our work suggests that CDK inhibitor drugs could fill this niche. R-roscovitine inhibits the activity of the CDKs 2, 5, 7 and $9 .{ }^{14,15}$ CDKs 2, 7 and 9 all have roles in the regulation of transcription by the holoenzyme RNApol II. ${ }^{14,15}$ This effect is mediated by phosphorylation of the C-terminal domain (CTD) and is inhibited by R-roscovitine in other cell systems. ${ }^{16}$ The transcriptional capabilities of neutrophils have been questioned; however, key studies have demonstrated that neutrophils are transcriptionally active and that this function has great importance in immune defence. ${ }^{17,18}$

This manuscript establishes for the first time in primary human neutrophils that CDK inhibitor-mediated inhibition of

${ }^{1}$ MRC Centre for Inflammation Research, The Queen's Medical Research Institute, University of Edinburgh Medical School, Edinburgh, Scotland, UK

${ }^{*}$ Corresponding author: AG Rossi, MRC Centre for Inflammation Research, The Queen's Medical Research Institute, University of Edinburgh Medical School, 47 Little France Crescent, Edinburgh, Scotland, UK. Tel: +44 131242 6659; Fax: +44 131242 6578; E-mail: a.g.rossi@ed.ac.uk

Keywords: neutrophil; apoptosis; inflammation; resolution; cyclin-dependent kinase

abbreviations: CDK, cyclin-dependent kinase; DRB, 5,6-dichloro-1-beta-D-ribofuranosylbenzimidazole; RNApol II, RNA polymerase II; P-TEFb, positive transcription elongation factor b; MAT1, ménage a trois 1; BAL, bronchoalveolar lavage; TFIIH, transcription factor IIH; CTD, C-terminal domain; 15 epi-LXA, 15 epi Lipoxin A4 Received 13.10.11; revised 30.4.12; accepted 16.5.12; Edited by G Rabinovich; published online 29.6.12 
CDKs 7 and 9 prevents RNApol II phosphorylation leading to specific effects on transcriptional capacity, promoting apoptosis.

\section{Results}

CDK and protein synthesis inhibitors induce neutrophil apoptosis. Figure 1 demonstrates the time-course of neutrophil viability following CDK inhibitor drug treatment (R-roscovitine, Figures 1a and b; DRB (5,6-dichloro-1-betaD-ribofuranosylbenzimidazole), Figure 1b). Effects of CDK inhibitor drugs were similar to that observed with the transcription inhibitor actinomycin-D (Figure 1a) and the translation inhibitor cycloheximide (data not shown). ${ }^{24}$ R-roscovitine (as we have previously shown ${ }^{7}$ ), DRB and actinomycin-D promote apoptosis as determined by cell morphology (Figure 1c) and flow cytometry (Figure 1d).

Key regulators of RNApol II-mediated transcription in neutrophils. Using genechip technology, we identified CDK gene expression levels in untreated/unstimulated neutrophils compared with neutrophils stimulated with LPS (Escherichia coli O127:B8, a bacterial product that delays neutrophil apoptosis ${ }^{3,25}$ ), R-roscovitine or LPS plus R-roscovitine (Figure 2). The most strongly expressed CDKs were CDKs 7 and 9 (Figure 2a). Interestingly, LPS stimulated CDKs 2 and 7 gene expression (Figure 2a) that was inhibited by $>50 \%$ by R-roscovitine. The cyclin-binding partners of CDK7 and 9 (cyclin $\mathrm{H}$ and cyclin T1, respectively) were expressed at higher levels than other cyclins (cyclin D1 shown for comparison; Figure 2b). Cyclin $\mathrm{H}$ expression was negatively regulated by R-roscovitine. MAT1 (ménage a trois 1; part of the transcription factor complex IIH (TFIIH) that contains CDK7) was expressed at low levels and unaffected by treatment. Endogenous CDK inhibitors, p21 variant (v)1 and $p 27$, were expressed at the gene level and p21v1 was upregulated by LPS treatment (Figure 2c). By comparison, p21v2 was only minimally expressed.

Western blotting of neutrophil total lysates was performed to investigate expression of CDKs at the protein level. We initially concentrated on CDKs known to be inhibited by R-roscovitine. CDK5, 7 and 9 were highly expressed, whereas CDK2 appeared to be minimally expressed with only a faint band observed (Figure 3a). Low levels of CDK2 protein in human neutrophils were confirmed by comparing lysates with those prepared form the proliferating cell lines HL-60 and HepG2 (Figure 3c). Differential nuclear and cytoplasmic lysis was subsequently performed to investigate the sub-cellular distribution of CDK proteins (Figure 3b). Antibodies to GAPDH and histone $\mathrm{H} 3$ confirmed differential fractionation, with GAPDH being exclusively cytoplasmic and a histone $\mathrm{H} 3$ complex predominantly expressed in the nuclear fraction. The minimal CDK2 that was observed appeared to be preferentially located in the cytoplasmic fraction (Figure 3b).
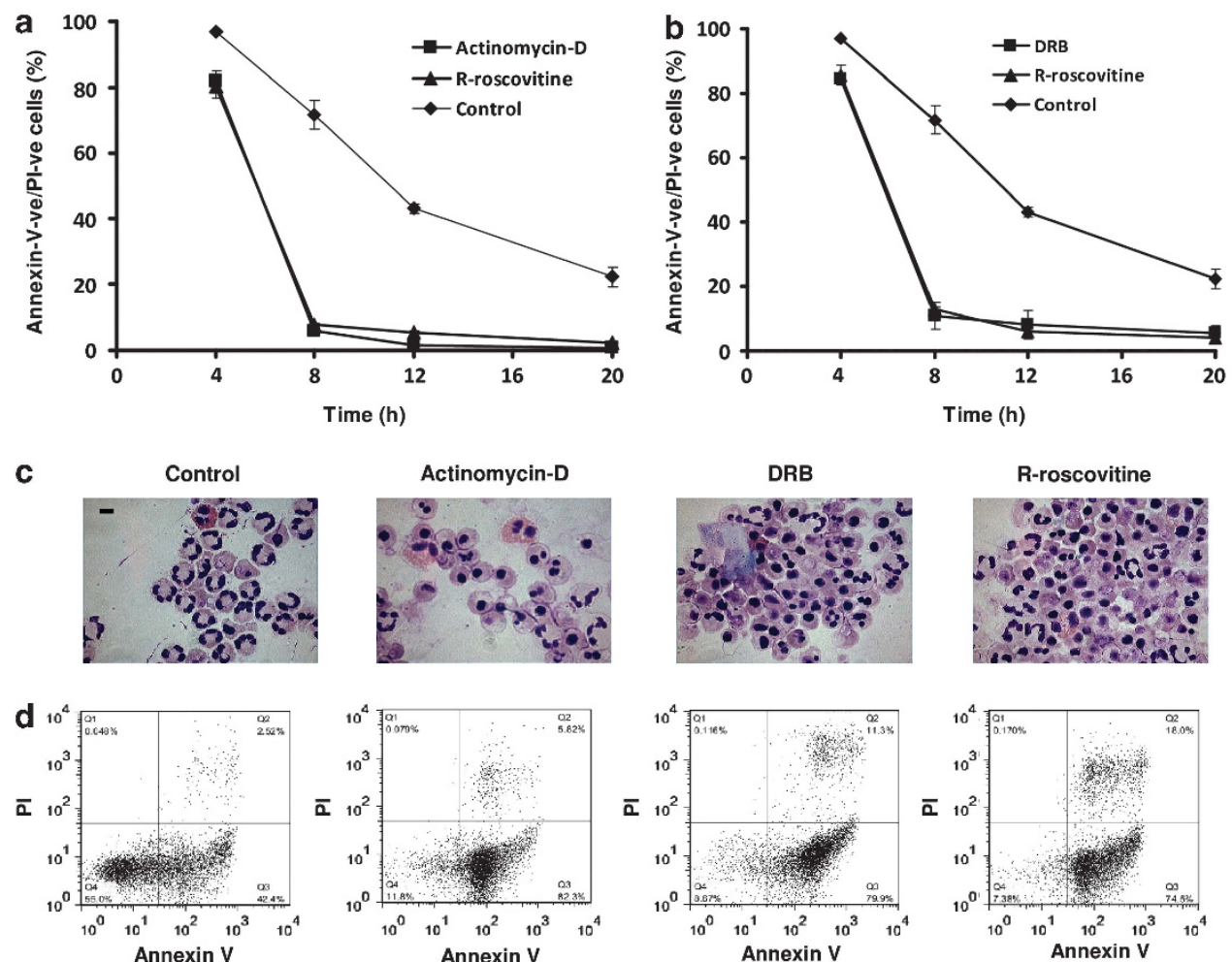

Figure 1 The CDK inhibitors R-roscovitine and DRB and the transcription inhibitor actinomycin-D drive human neutrophil apoptosis. (a and $\mathbf{b})$ Time-course showing the change in neutrophil viability (defined as annexin-V-ve/PI-ve) over a 20-h time period in control, R-roscovitine $(20 \mu \mathrm{M})$, actinomycin-D (10 $\mu \mathrm{M})$ or DRB $(20 \mu \mathrm{M})$-treated cells. (c) Representative cytocentrifuge preparations for examination of morphological changes associated with apoptosis (scale bar $5 \mu \mathrm{m}$ ) and (d) representative flow cytometric analysis of annexin- $\mathrm{V}$ binding and PI staining plots at $8 \mathrm{~h}$ of culture. Data are representative of $n=3$ experiments of three separate replicates and are presented as mean \pm S.E.M. 
CDK5 was readily detected and was distributed between the cytoplasmic and nuclear fractions. There appeared to be an increase in the nuclear fraction of CDK5 on stimulation with LPS that was blocked by co-treatment with R-roscovitine. CDK7 was readily detected in both cytoplasmic and nuclear fractions. Both isoforms ( 55 and $43 \mathrm{kDa}$ ) of CDK9 were readily detected in the neutrophils and appeared equally distributed between nuclear and cytoplasmic fractions. There was no obvious effect of LPS stimulation or R-roscovitine treatment on the distribution or levels of either isoform of CDK9. The binding partner cyclins of CDKs 7 and 9 (cyclin $\mathrm{H}$ and cyclin $\mathrm{T} 1$, respectively) were predominantly expressed in the nuclear fraction and there was minimal impact of LPS stimulation or R-roscovitine treatment on this distribution (Figure 3b).

To further investigate the western blotting observations for CDK7 and 9, confocal microscopy was performed in both unstimulated and LPS-stimulated neutrophils (Figures $3 d-g$ ). CDKs 7 and 9 were identified within the nucleus and cytoplasm by confocal imaging in both conditions that confirmed our western blotting data.

The CDK inhibitor drug R-roscovitine modulates phosphorylation of RNApol II in neutrophils. Recently, it had become apparent that neutrophils indeed have a capacity for de novo transcription. ${ }^{17,26,27}$ The aim of this experiment was to identify neutrophil transcriptional machinery and to seek evidence for the involvement of CDKs 7 and 9 in the regulation of transcription. Phosphorylation of the CTD of RNApol II, which consists of 52 repeats of heptapeptide Tyr1Ser2-Pro3-Thr4-Ser5-Pro6-Ser7 (YSPYSPS), provides a functional assay for CDK7 and 9 activity. CDK7 phosphorylates RNApol II serine 5, whereas CDK9 phosphorylates predominantly serine 2 (though it can phosphorylate both under certain conditions in different cell types). In Figure 4, the total RNA polymerase protein complex and RNA polymerase phosphorylated on key serine residues at position 2 (PS2) and 5 (PS5) are identified by western blotting with densitometry quantification. Phosphorylation on these serine residues is of known importance to the regulation of transcription by CDKs 7 and 9 . Significant time-dependent loss of phosphorylation at serine residues 2 and 5 when neutrophils were incubated with the CDK inhibitor R-roscovitine is shown (Figures $4 \mathrm{a}-\mathrm{c}$ ). There was no significant change in total RNApol II with R-roscovitine treatment (Figure 4d). In addition, the RNApol II protein was identified in untreated neutrophils by indirect immunofluorescence detected by confocal microscopy (Figure 4e). It appeared that RNApol II levels were enhanced following stimulation of neutrophils with LPS, consistent with enhancement of active gene transcription.
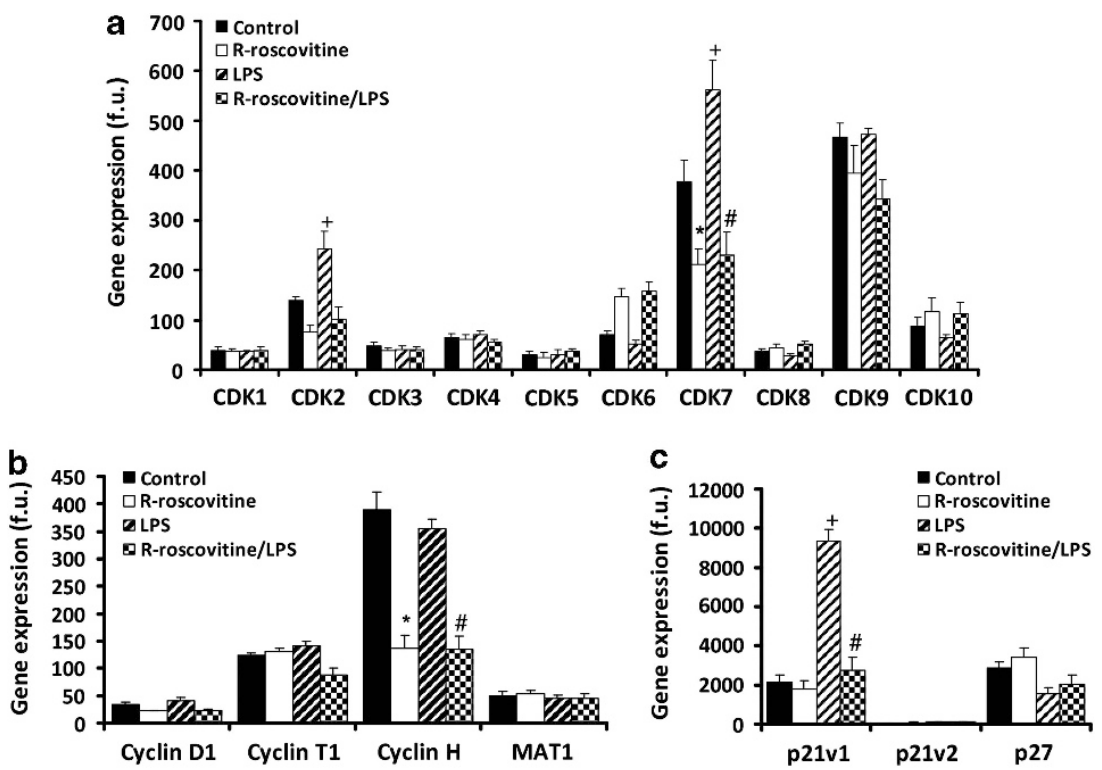

Figure 2 Analysis of CDKs, cyclins and endogenous CDK inhibitors in human neutrophils. Expression levels of human neutrophil CDKs (a), cyclins (b) and endogenous CDK inhibitors (c) as analysed by Illumina Gene Chip. Neutrophils isolated from four independent donors $(n=4)$ and treated for $4 \mathrm{~h}$ with media alone (Control), R-roscovitine $(20 \mu \mathrm{M})$, LPS $(100 \mathrm{ng} / \mathrm{ml})$ or a combination before RNA isolation and interrogation by microarray. Result shows gene expression levels (fluorescence units, f.u.) as mean \pm S.E.M. Significant differences $P<0.001$ between Control and R-roscovitine are shown as *, between LPS and R-roscovitine/LPS as \#, and between LPS and control by + , analysed using ANOVA with post hoc multivariate analysis by Student's Newman-Keuls

Figure 3 Human neutrophils express CDKs and their cyclin binding partners. (a) Whole cell or (b) cytoplasmic/nuclear differential lysates prepared after $4 \mathrm{~h}$ incubation in control, R-roscovitine $(20 \mu \mathrm{M})$, LPS $(100 \mathrm{ng} / \mathrm{ml})$ or R-roscovitine and LPS and blotted for CDKs known to be inhibited by R-roscovitine as well as the cyclin binding partners of CDKs 7 and 9. (c) Low levels of CDK2 in human neutrophils confirmed using the proliferating cell lines HL-60 and HepG2 as a positive control. Densitometry on $n=3$ presented as mean \pm S.E.M., analysed using ImageJ software. All gels are representative of at least $n=3$ experiments. Confocal microscopy in neutrophils either unstimulated (d and $\mathbf{e}$ ) or stimulated with LPS (100 $\mathrm{ng} / \mathrm{ml}$ ) (f and $\mathbf{g}$ ) and probed for CDK7 (d and f) or 9 (e and $\mathbf{g}$ ) by indirect immunofluorescence. Panels show transmitted light/bright field (BF), DAPI nuclear staining (blue), and CDK7 or 9 staining (red), final panel shows merged image (MERGE) demonstrating nuclear co-localisation (pink). Size bar represents $5 \mu \mathrm{m}$ scale. Leica SP confocal microscope $\times 630$ oil immersion. Representative images from at least $n=3$ experiments 
R-roscovitine affects global gene transcription in LPSstimulated and -unstimulated primary human neutrophils. In Figure 5, global effects on gene expression for neutrophils treated with R-roscovitine are illustrated by representative bar graphs and a heat-map. The heat-map shows the genes most significantly up and downregulated across all the four treatment conditions (untreated neutrophils (C), R-roscovitine-treated (R), LPS-stimulated (L)

a

b
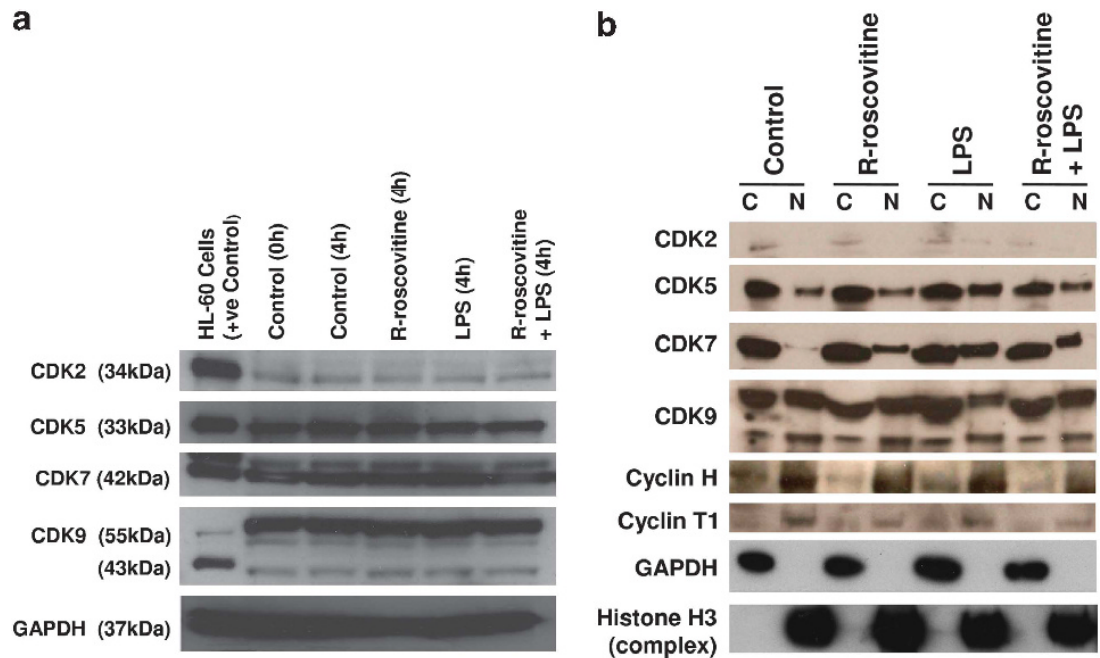

Cyclin T1

GAPDH

Histone $\mathrm{H} 3$

(complex)

c
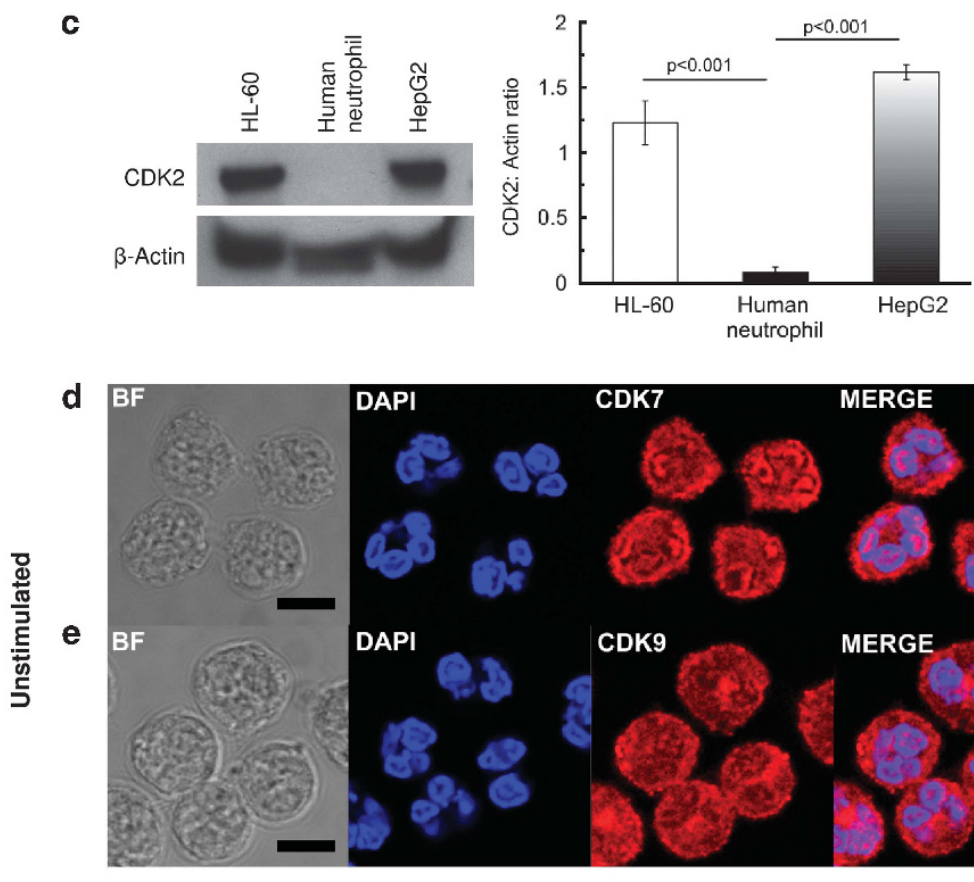

CDK7

MERGE

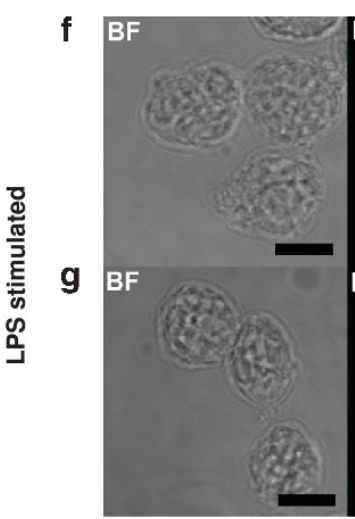

DAPI CDK7
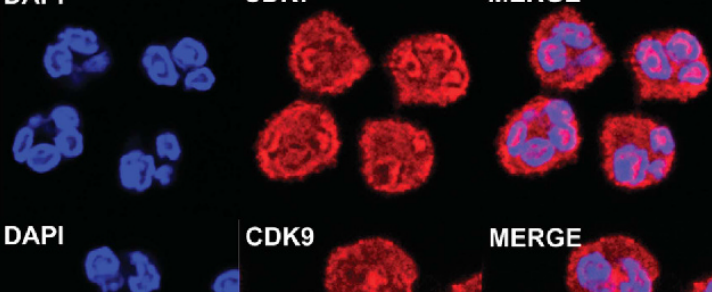

CDK9
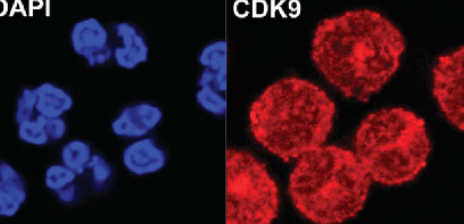

MERGE

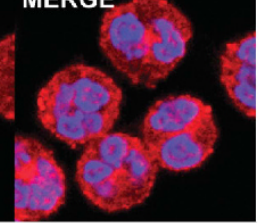

MERGE
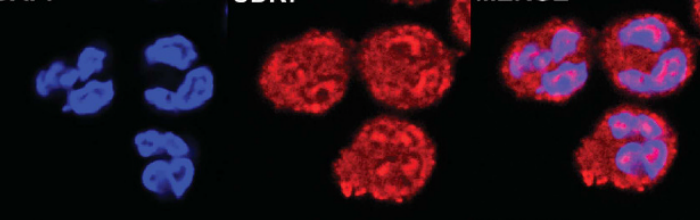

DAPI

CDK9

MERGE

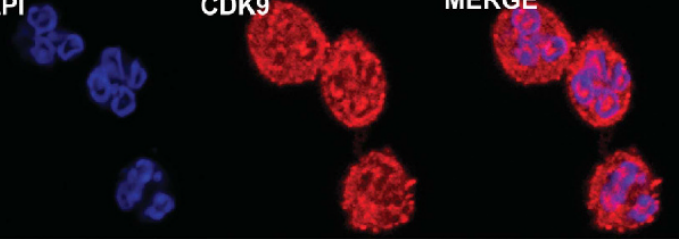


a

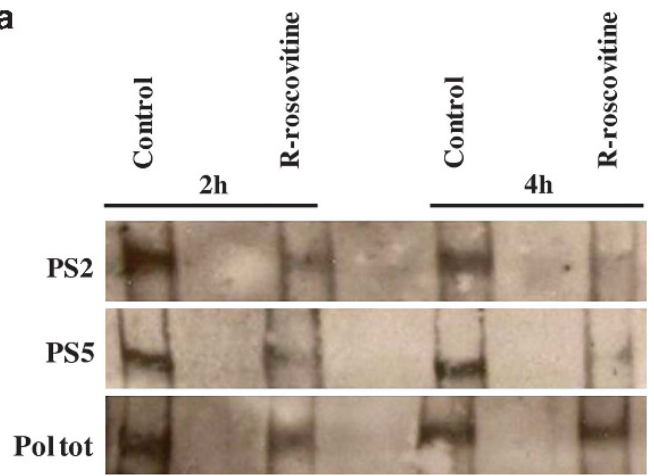

b

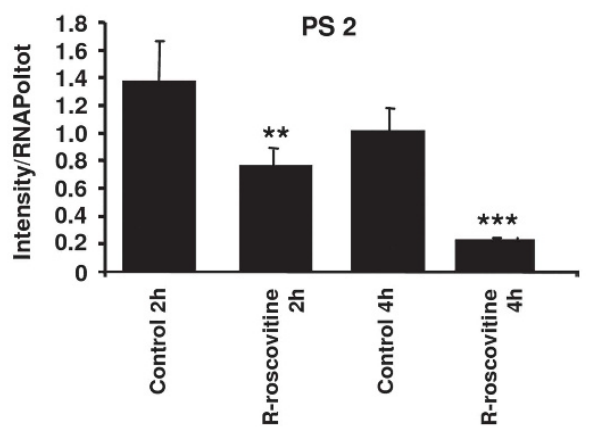

\section{C}

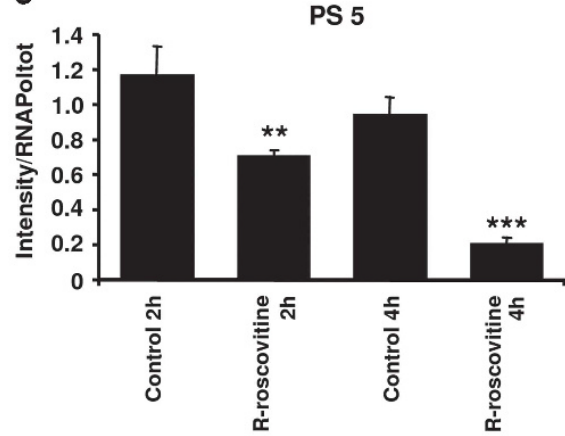

Pol tot

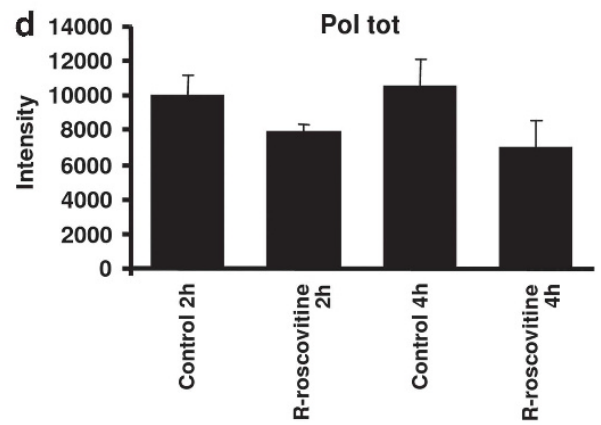

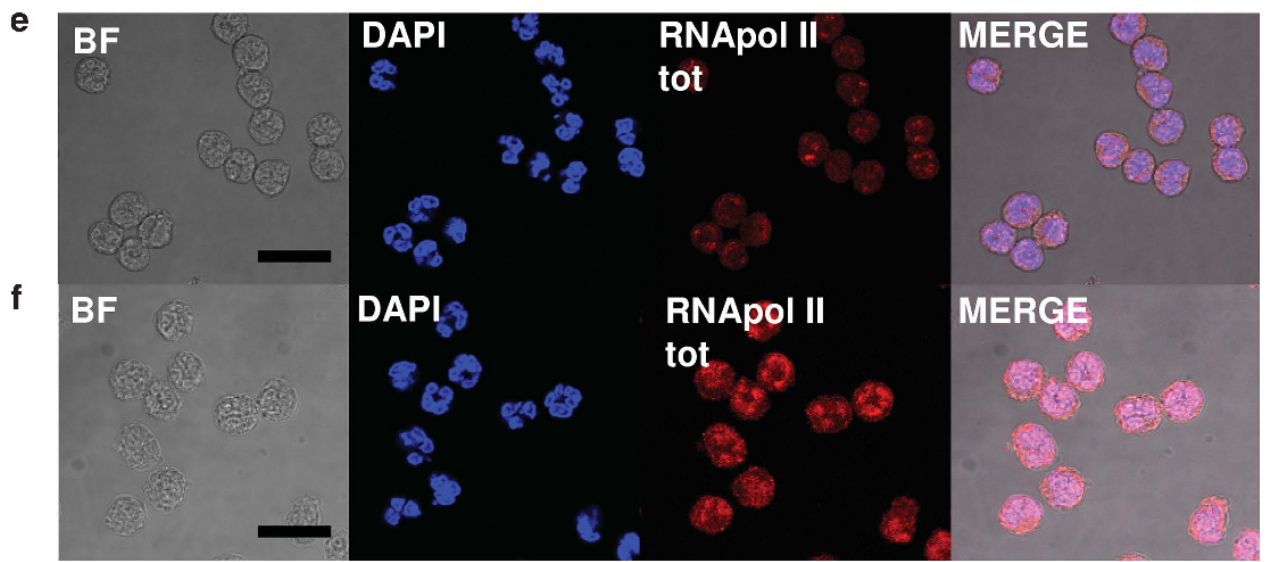

Figure 4 R-roscovitine inhibits RNApol II phosphorylation on serine 2 and serine 5. (a) Western blotting for RNApol II total (Pol tot), phosphorylated on serine 2 (PS2) and phosphorylated on serine 5 (PS5) after 2 and $4 \mathrm{~h}$ in control or R-roscovitine $(20 \mu \mathrm{M})$ treated neutrophils. Lysates were run on $4 \%$ acrylamide gels with blots shown representative of three experiments. Densitometry $(n=3$, mean \pm S.E.M.) for serine 2 (b) and serine 5 (c), normalised to total RNApol II levels (d). Statistical significance compared to relevant time-point control where $P<0.01$ is shown as ${ }^{* *}$ and $P<0.001{ }^{* * *}$ by ANOVA with post hoc multivariate analysis by Student's Newman-Keuls (with a $95 \%$ confidence interval). Confocal microscopy of RNApol II (total) in neutrophils either unstimulated (e) or stimulated with LPS (100 $\mathrm{ng} / \mathrm{ml}$ ) (f) by indirect immunofluorescence. Panels show transmitted light/bright field (BF), DAPI nuclear staining (blue), RNApol II (total) staining (red), final panel shows merged image (MERGE) demonstrating nuclear colocalisation (pink). Size bar represents $10 \mu \mathrm{m}$ scale. Leica SP confocal microscope $\times 630$ oil immersion. Representative images are shown from $n=3$ experiments

and LPS/R-roscovitine co-treatment $(R L))$. In the total of genes detected, 1656 genes were downregulated, 886 were upregulated and 1359 were not significantly affected following treatment with R-roscovitine for $4 \mathrm{~h}$. Genes related to transcription were highly represented in terms of differential regulation following R-roscovitine treatment. In Figure 5, the impact on transcription-related genes as well as data for further gene types of specific interest to this work (apoptosis, inflammation, cell-cycle) are clearly demonstrated. The general trend is of gene downregulation following R-roscovitine treatment. Using gene ontology cluster analysis (Table 1), it was possible to identify clusters of genes that are most affected by R-roscovitine treatment.

Differential effect of the CDK inhibitor drug R-roscovitine on regulators of neutrophil apoptosis. We hypothesised that if the mechanism of action of R-roscovitine-driven neutrophil apoptosis was related to an effect on transcription, it might be prevented or at least delayed by the stabilisation of $\mathrm{Mcl}-1$. This might have been achieved by transfection/transduction approaches, but these techniques have yet to be consistently and reliably applied to 

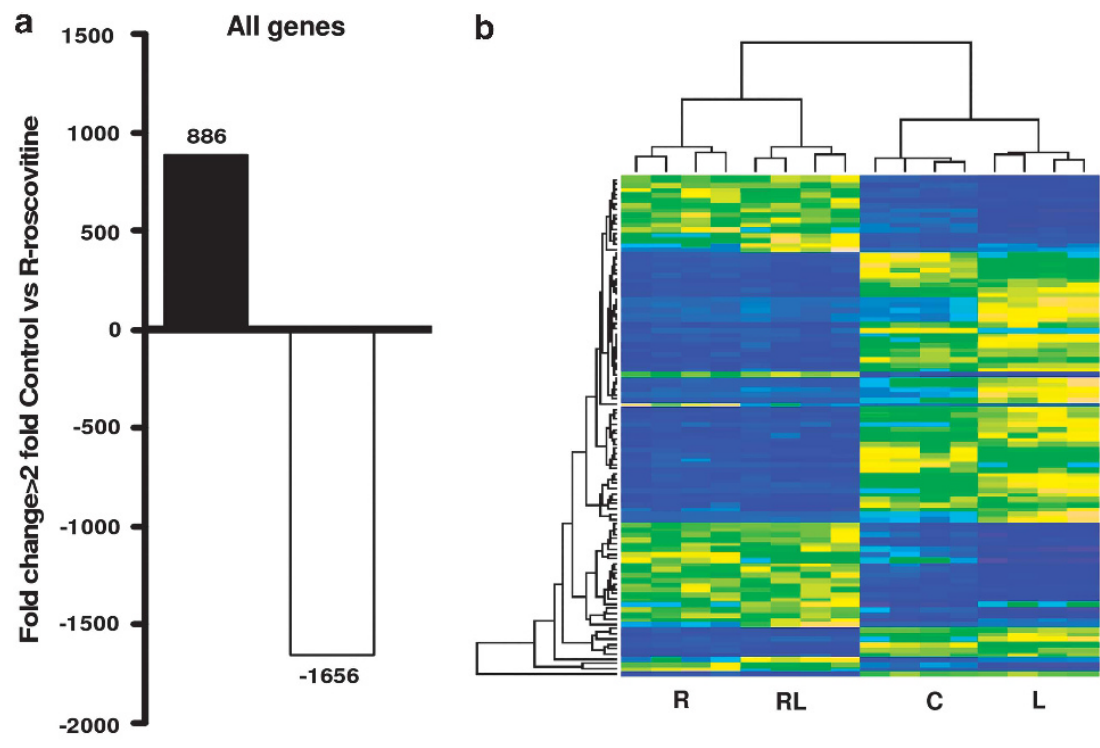

C Transcription

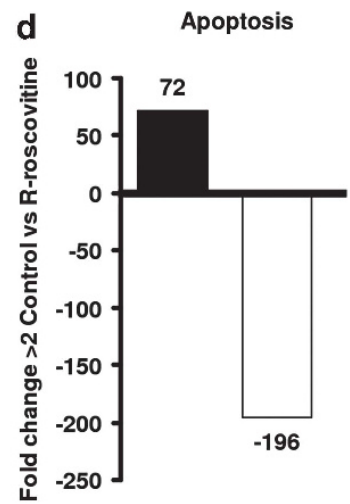

e
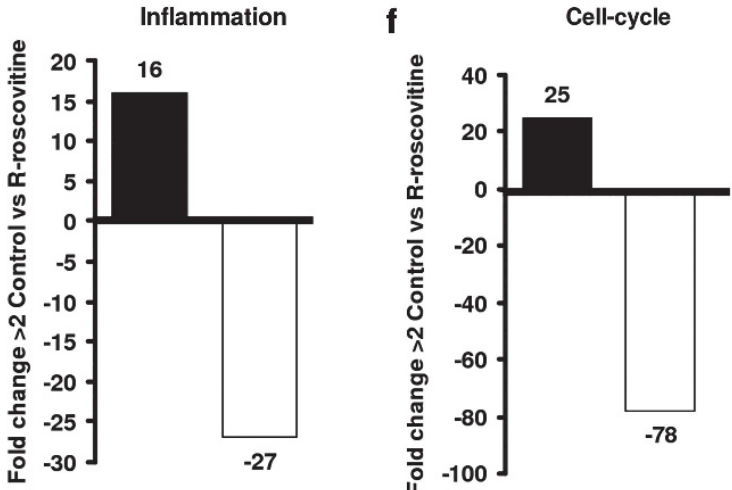

Figure 5 R-roscovitine effects on the neutrophil transcriptome. Neutrophils treated for $4 \mathrm{~h}$ with media alone or R-roscovitine $(20 \mu \mathrm{M})$ were subjected to RNA isolation before interrogation by Illumina Gene Chip microarray. (a) Bar graph shows number of genes down-regulated ( $>2$ fold) and up-regulated ( $>2$ fold) by R-roscovitine treatment compared to control. Specific gene families assessed include: (c) transcription, (d) apoptosis, (e) inflammation and (f) cell-cycle. (b) Heat map shows gene expression most changed (upregulated and downregulated) across the four treatment groups of R-roscovitine (R), R-roscovitine/LPS (RL), Control (C) and LPS alone (L). Neutrophils from 4 donors $(n=4)$

primary human neutrophils. ${ }^{28}$ Therefore co-treatment with a proteasome inhibitor was utilised. Mcl-1 is an unusual $\mathrm{Bcl}-2$ homologue in that it has a PEST domain that targets it for degradation in the proteasome in under $2 \mathrm{~h} .{ }^{11}$ Figure $6 \mathrm{a}$ shows that R-roscovitine-mediated loss of neutrophil viability was reversed at 8 and $12 \mathrm{~h}$ with the proteasome inhibitor
MG-132. MG-132 treatment, even in the presence of R-roscovitine, prevented loss of $\mathrm{Mcl}-1$ protein levels (Figure 6b). This was in contrast to the use of the caspase inhibitor z-VAD-fmk that did not prevent R-roscovitineinduced Mcl-1 downregulation (Figure 6b). Prevention of neutrophil apoptosis with MG-132 was only evident if MG- 
Table 1 Gene ontology analysis of neutrophil gene-clusters most affected by R-roscovitine treatment

\begin{tabular}{lll}
\hline & Downregulated genes $(>$ twofold $\boldsymbol{P}<\mathbf{0 . 0 1})$ & Upregulated genes $(>$ twofold $\boldsymbol{P}<\mathbf{0 . 0 1 )}$ \\
\hline 1 & Positive regulation of I-kappaB kinase/NF- $\kappa$ B cascade & Translational elongation \\
2 & Response to unfolded protein & Ribosomal small subunit biogenesis \\
3 & Protein transport & Immune response \\
4 & Regulation of programmed cell death & rRNA processing \\
5 & Regulation of transcription from RNApol II promoter & Leukocyte activation during immune response \\
6 & Protein localisation & Lysosomal transport \\
7 & Cell cycle & Negative regulation of interleukin-8 biosynthetic process \\
8 & mRNA processing & Positive regulation of pinocytosis \\
9 & Transcription initiation from RNA polymerase II promoter & Defence response to fungus \\
10 & Positive regulation of transcription & Leukocyte activation \\
\hline
\end{tabular}

Illumina Gene Chip technology experiment on $n=4$ donors. Over-represented gene ontology terms in genes significantly up and downregulated (up and downregulation $>$ twofold, R-roscovitine compared to control with significance of $P<0.001$ )
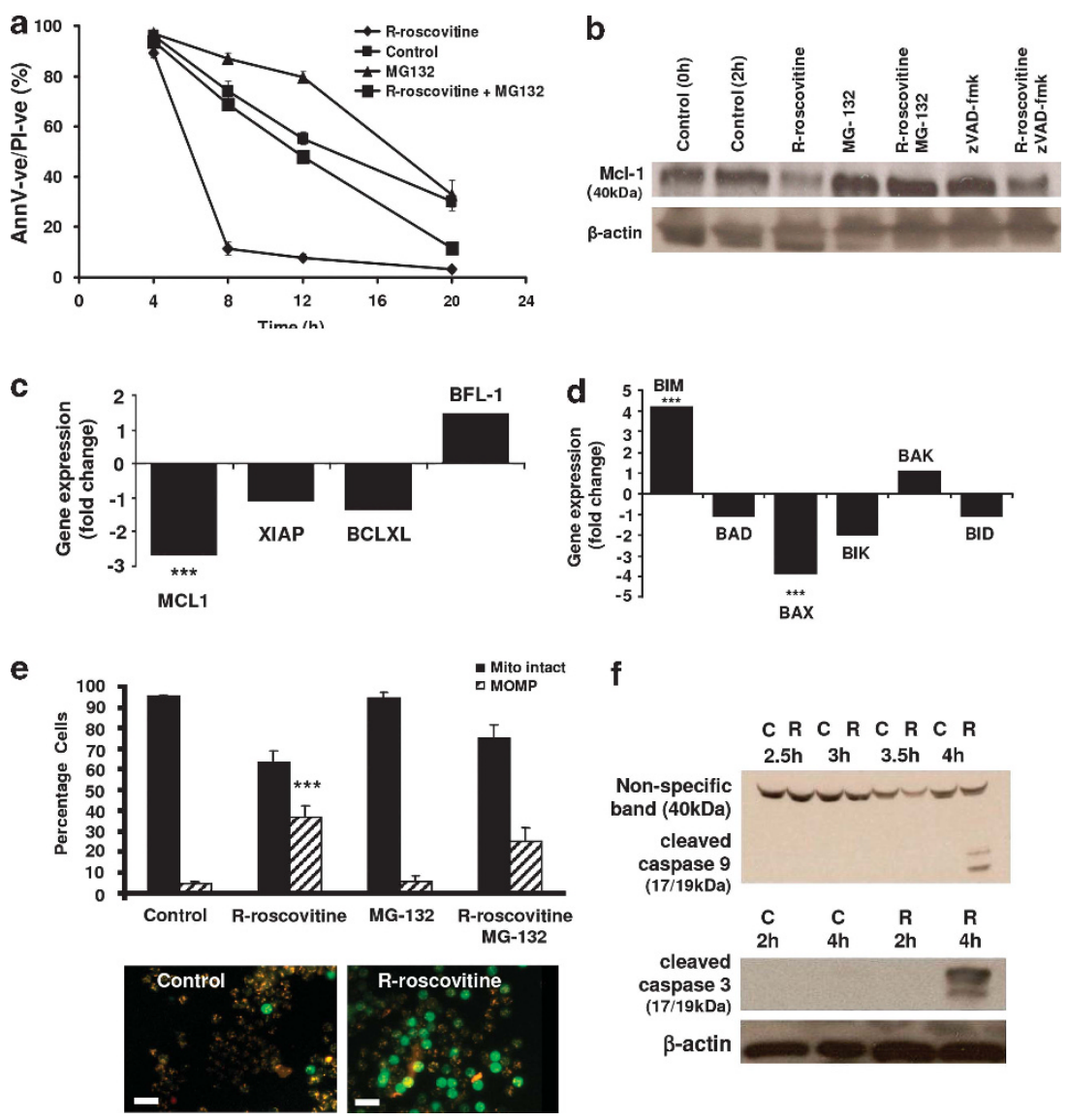

Figure 6 R-roscovitine effects on apoptotic pathways. (a) Neutrophil viability assessed using flow cytometry for annexin-V/PI following culture with media alone (Control), R-roscovitine $(20 \mu \mathrm{M})$, MG-132 $(50 \mu \mathrm{M})$ or with a combination of R-roscovitine and MG-132. (b) Neutrophils at $5 \times 10^{6} / \mathrm{ml}$ in IMDM containing $10 \%$ autologous serum were either lysed immediately (time 0 ) or incubated in either the absence (control) or presence of R-roscovitine (20 $\mu \mathrm{M})$, MG132 (50 $\mu \mathrm{M})$, zVAD-fmk (100 $\mu \mathrm{M})$ or combinations of these agents for $2 \mathrm{~h}$, then lysed and immunoblotted for Mcl-1 or $\beta$-actin. Blots shown are representative of three experiments. (c and d) Effect of $4 \mathrm{~h}$ R-roscovitine $(20 \mu \mathrm{M})$ on gene expression of bcl-2 homologues (anti-apoptotic (c), pro-apoptotic (d)) measured by Illumina gene chip ( $n=4$ donors). Result shows fold change in gene expression with statistical significance $P<0.001$ shown by ${ }^{* * *}$. (e) Mitochondrial membrane integrity analysed by mitocapture dye after $2 \mathrm{~h}$ incubation in medium alone (control), R-roscovitine (20 $\left.\mu \mathrm{M}\right)$ alone, MG-132 $(50 \mu \mathrm{M})$ or combined R-roscovitine and MG-132. Mitocapture fluoresces red/orange in the mitochondria of viable neutrophils (Mito intact, solid bars) and green in the cytoplasm of neutrophils with loss of mitochondrial outer membrane (transmembrane) potential (MOMP, striped bars; fluorescent microscopy $\times 320$, scale bar $20 \mu \mathrm{m}$ ). (f) Western blotting for cleaved (active) caspases 9 and 3 after incubation with media alone (c) or R-roscovitine $20 \mu \mathrm{M}(\mathrm{R})$ at the given time points. All experiments $(n=3)$. Statistical significance compared to relevant time-point control $P<0.001$ is shown as ${ }^{\star \star \star}$ by ANOVA with post hoc multivariate analysis by Student's Newman-Keuls (with a $95 \%$ confidence interval)

132 was administered within $2 \mathrm{~h}$ of R-roscovitine treatment (data not shown), suggesting that $\mathrm{Mcl}-1$ loss was an early and key event in the induction of apoptosis.
To support the hypothesis that $\mathrm{Mcl}-1$ is essential to neutrophil survival and that its downregulation by R-roscovitine leads to apoptosis, it was important to show that pro-apoptotic bcl-2 
homologues were not downregulated in a similar fashion. The pro-apoptotic bcl-2 homologue Bim is prominent in neutrophil apoptosis and is especially relevant to apoptosis of cytokine-stimulated neutrophils. ${ }^{12}$ Other bcl-2 homologues of relevance to neutrophil apoptosis include Bax, Bid and Bad. We have shown that Bim protein is preserved throughout a 4-h treatment with R-roscovitine. ${ }^{13}$ At the level of gene expression, Bim was significantly upregulated, whereas Bax was significantly downregulated and other pro-apoptotic Bcl-2 homologues remained unaffected (Figure 6d). Pro-survival $\mathrm{Bcl}-2$ homologues were unaffected at gene expression level, apart from $\mathrm{Mcl}-1$, which was significantly downregulated (Figure 6c).

To further assess the relevant apoptotic pathways, we investigated mitochondrial membrane integrity (Figure 6e). Mitocapture dye accumulates in mitochondria of viable cells and fluoresces orange/red, whereas in the apoptotic cells, it leeches out of permeabilised mitochondria into the cytoplasm where it fluoresces green. Using this dye, we demonstrated significant induction of mitochondrial permeabilisation by R-roscovitine at early time-points where there was no evidence of morphological changes of apoptosis. Western blotting for the pro-apoptotic protein Bid revealed no evidence of cleavage throughout the time-range where apoptosis occurred (data not shown). R-roscovitine activated the caspase cascade, with the evidence of caspase- 9 and -3 cleavage (activation) by western blotting after $4 \mathrm{~h}$ incubation (Figure 6f).

The CDK inhibitors DRB and R-roscovitine drive resolution of inflammation in the bleomycin-induced lung injury model. We investigated the ability of CDK inhibitor drugs to resolve neutrophilic inflammation associated with the bleomycin lung injury model (Figure 7a). Bleomycininduced lung injury has been a gold standard model for investigation of lung inflammation and fibrosis with similar pathology to the human disease idiopathic pulmonary fibrosis. Mice subjected to bleomycin injury develop significant bronchoalveolar lavage (BAL) neutrophilia (Figure 7b) and a measurable increase in BAL protein (Figure $7 d$ ) on day 7 consistent with inflammatory injury. By contrast, mice subjected to bleomycin injury, but treated with DRB or R-roscovitine, have less neutrophils in BAL with no detrimental effect on macrophage numbers (Figures $7 b$ and $c$ ). Additionally, there is significantly less protein in BAL of CDK inhibitor-treated mice compared with vehicle controls (Figure 7d). There is an apparent trend towards less cell damage as measured by lactate dehydrogenase release in BAL of CDK inhibitor-treated mice but this did not reach statistical significance (Figure 7e). Histological evidence of neutrophil-dominant inflammation was clear in control animals at day 7, but in R-roscovitine- or DRB-treated animals, the inflammation was markedly attenuated with reductions in inflammatory cell infiltration in the alveoli, peri-bronchiolar and peri-vascular areas (Figure 7f). This is in contrast to untreated mice where neutrophils persist and significant architectural disturbance occurs resulting in fibrosis. To increase the novelty of this experiment and to further assess the potential of CDK inhibitor drugs to translate to clinical therapeutics, it should be noted that we delivered the CDK inhibitors via the i.t. route to mimic the delivery of standard inhaled therapies. This allowed us to decrease the total dose delivered to $10 \mathrm{mg} / \mathrm{kg}$ (a 10-fold lower dose than used in our previous study ${ }^{7}$ ).

\section{Discussion}

Our discovery that CDK inhibitor drugs (specifically R-roscovitine and DRB) induce neutrophil apoptosis was unexpected given the cell cycle status of terminally differentiated neutrophils. The only other terminally differentiated cell type (neurons) studied with these pharmacological agents demonstrated enhanced longevity. ${ }^{29}$ Moreover, Klausen et al., ${ }^{30}$ using primary healthy human bone-marrow cells, described progressive loss of CDKs 2, 4 and 6, which began at the myelocyte/metamyelocyte stage and was almost complete by full maturation. This coincided with upregulation of the endogenous CDK inhibitor p27kip1. No consistent finding with regard to the up or downregulation of the CDK-binding partners, termed cyclins, was obtainable illustrating the complexity of regulation involved in this system. This finding was important as other works on granulopoiesis had utilised a variety of cell lines and discovered several CDK/CDK-binding partner expression patterns. Interestingly, the endogenous CDK inhibitor $\mathrm{p} 21$ has been described as a novel modulator of the macrophage response to LPS. ${ }^{31,32}$ We have demonstrated functional CDKs, their binding partners and endogenous inhibitors and transcriptional machinery (both at gene and protein level) and identified specific transcriptional effects of the CDK inhibitor drugs in neutrophils. Perhaps unsurprisingly, given the terminally differentiated state of these cells, the most significantly expressed $\mathrm{CDKs}^{7,9}$ have no direct role in the cell cycle but are essential for transcription of a key subset of genes. ${ }^{33,34}$ This correlates well with our finding of a similarity in the kinetics of apoptosis induced by CDK inhibitor drugs and the protein transcription inhibitor actinomycin-D and the protein translation inhibitor cycloheximide.

The standard model of transcription from a promoter involves the binding and formation of a pre-initiation complex composed of RNApol II and various TATA box-binding proteins, kinases and ubiquitin ligases. This RNApol II holoenzyme is responsible for the majority of RNA transcription in mammalian cells. The pre-initiation complex requires further input before full-length, viable mRNA is produced. In highly inducible genes such as those involved in inflammatory signalling or apoptosis, RNApol II recruitment and activation occur simultaneously. These genes are heavily dependent on the positive transcription elongation factor $b$ (P-TEFb) complex. P-TEFb is a heterodimer of CDK9 and cyclin T1 that can phosphorylate serines 2 and 5 . Interestingly, $\mathrm{NF}-\kappa \mathrm{B}$-dependent genes are reliant on P-TEFb activity and there may be a physical interaction between NF- $\kappa \mathrm{B}$ and P-TEFb. ${ }^{35,36}$ CDK7, cyclin $\mathrm{H}$ and the cofactor MAT1 are part of the TFIIH that is important for the initiation of transcription. LPS stimulation enhances CDK7 gene transcription, suggesting that enhanced transcription directly drives transcription machinery production (Figure 2a). This process is downregulated by R-roscovitine. It should be noted that other proteins have been shown to have an effect on the phosphorylation status of the CTD of RNApol II including 

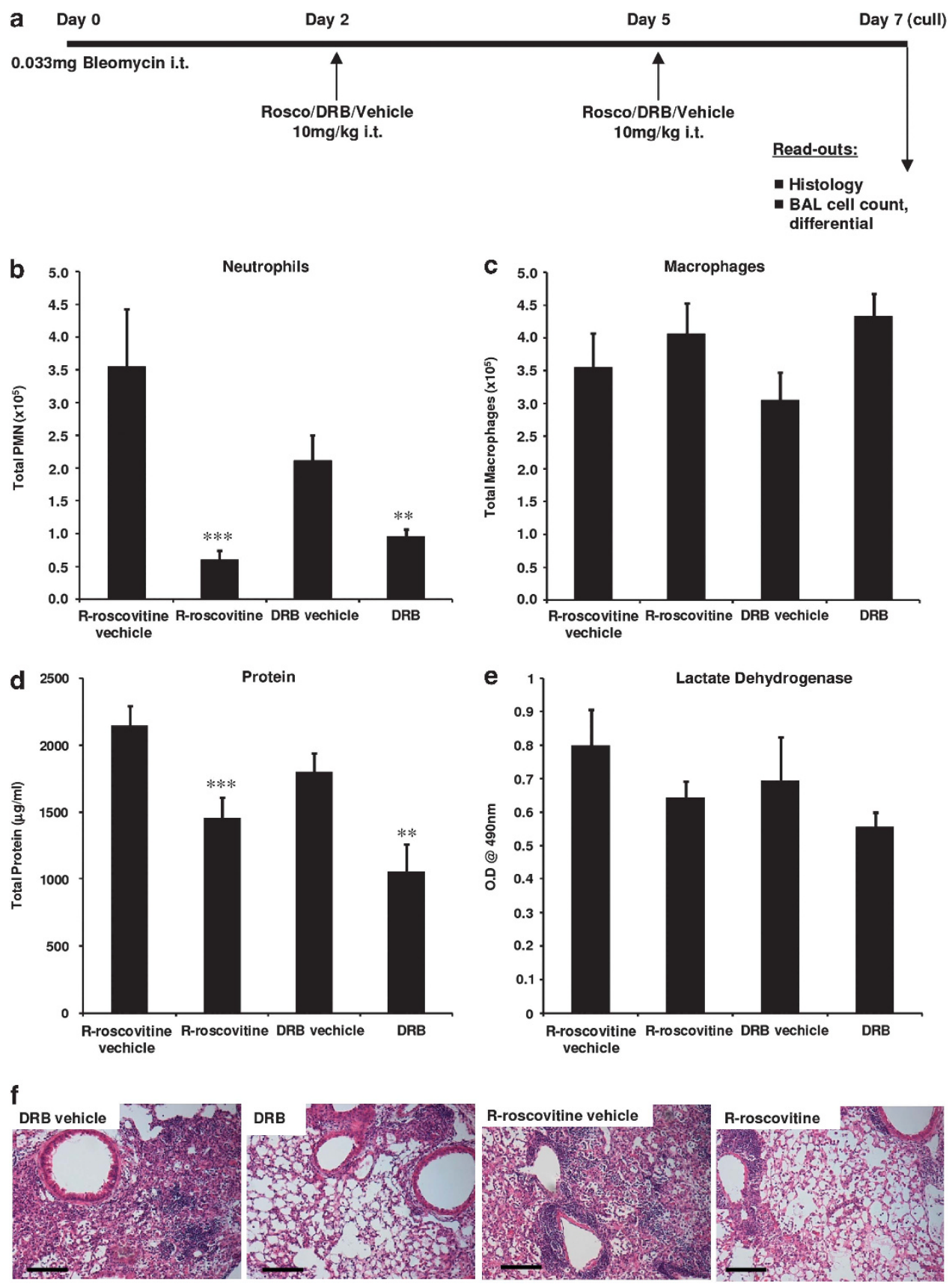

Figure 7 CDK inhibitors R-roscovitine and DRB resolve bleomycin-induced acute lung injury. (a) Schematic of experimental protocol. Analysis of BAL fluid at day 7 for (b) neutrophil numbers (c) macrophage numbers (d) total protein (e) lactate dehydrogenase. $n=5$, mean \pm S.E.M., statistically significant difference compared with vehicle control shown as ${ }^{\star *} P<0.01$ or ${ }^{* \star *} P<0.001$ by ANOVA with a Student's Newman-Keuls multiple comparison post hoc test with a $95 \%$ confidence interval. (f) Representative histological images (stained with haematoxylin and eosin) at magnification $\times 100$ (size bar $100 \mu \mathrm{m}$ scale)

CDK1, CDK2, CDK8 and ERK. ${ }^{38}$ Of these, CDK1 and 8 negatively regulate phosphorylation so their inhibition would be expected to result in increased phosphorylation and CDK2 has an indirect regulatory effect on CDK7. We have previously investigated ERK in the context of CDK inhibition and found no effect on its activity. ${ }^{14}$ In this manuscript, we show very minimal CDK2 expression at the protein level and almost none within the nucleus, so it would seem an unlikely target. Our work with the CDK7- and 9-specific inhibitor, DRB, also argues against a significant role for CDK2.

We hypothesised that it was inducible genes (short-lived, rapidly upregulated, responsive and dependent on CDK activation) that allow fine control of neutrophil apoptosis (Figure 6 and Table 1). To support this contention, we have demonstrated that RNApol II is both present in neutrophils and phosphorylated by CDKs 7 and 9 to enhance transcriptional 
capacity (Figure 4). Inhibition of CDKs 7 and 9 leads to dephosphorylation of this enzyme and downregulation of transcription. The transcriptional capacity of neutrophils has been a matter of some controversy. Work by Cassatella et al. ${ }^{18}$ suggested that neutrophils do have the capacity for de novo transcription. ${ }^{17,26}$ Here, we describe the machinery by which they achieve this functionality and a method by which it may be selectively altered to enhance apoptosis and resolution of inflammation.

Mcl-1 protein levels are rapidly downregulated by $\mathrm{R}$-roscovitine before the induction of apoptosis (Figure 6). Inhibiton of the proteasome by MG-132 prevented both R-roscovitine-induced Mcl-1 downregulation and apoptosis. Although caspase inhibition by z-VAD-fmk prevented neutrophil apoptosis, this did not fully prevent $\mathrm{Mcl}-1$ downregulation, suggesting $\mathrm{Mcl}-1$ downregulation occurs upstream of caspase activation (Figure 6). It was important to examine the expression of other pro-apoptotic and antiapoptotic bcl-2 homologues to present a comprehensive picture of apoptosis signalling within the CDK inhibitor-treated neutrophil. We have previously shown that Bim, a key proapoptotic bcl-2 homologue mediating neutrophil apoptosis, is maintained at the protein level despite R-roscovitine treatment. ${ }^{13}$ The Bim knockout mouse phenotype had enhanced neutrophil survival ${ }^{37}$ and two recent papers have shown Bim upregulation in neutrophils in models of inflammation in vitro and in vivo. ${ }^{12,38}$ Our data are consistent with a relative excess of pro-apoptotic bcl-2 homologues occurring following downregulation of survival proteins (notably $\mathrm{Mcl}-1$ ) by CDK inhibitor drugs, the net result being loss of mitochondrial membrane integrity and apoptosis. Mcl-1 is downregulated at the gene expression level by R-roscovitine and we hypothesise that this precedes and is responsible for the initiation of apoptosis as we measured changes in the level of this mRNA/ protein at $2 \mathrm{~h}$ but detected only a small percentage of apoptosis by $4 \mathrm{~h}$.

By demonstrating that $\mathrm{Mcl}-1$ is downregulated at the level of gene expression, we corroborate our finding that direct inhibition of NF- $\kappa \mathrm{B}$ is not responsible for CDK inhibitor-driven neutrophil apoptosis. ${ }^{13}$ We hypothesise that a more central, generalised effect on neutrophil transcription is responsible for the induction of apoptosis. This effect is particularly evident in granulocytes because of the importance of the short-lived protein $\mathrm{Mcl}-1$ to their survival. The imbalance between $\mathrm{Mcl}-1$ and Bim drives neutrophils towards the intrinsic apoptosis pathway. Neutrophils are extremely sensitive to the changes in the inflammatory and immune milieu, and their dependence on a highly regulated survival protein is an explanation for their rapid regulation of apoptosis. Our work adds to the literature, suggesting the fundamental importance of these proteins to neutrophil survival, and more importantly describes the fundamental mechanism of action of the CDK inhibitor drugs in the resolution of inflammation. Finally, we demonstrate the ability of a CDK7/9-specific pharmacological agent (DRB) to resolve lung inflammation in a well-characterised in vivo model.

The work herein provides an insight into the transcriptional machinery of the neutrophil and demonstrates that CDK inhibition is an appealing strategy for the manipulation of this machinery to drive neutrophil apoptosis. Importantly, we believe our findings will help to advance future trials of CDK inhibitor drug therapy in the promotion of resolution of inflammation.

\section{Materials and Methods}

Neutrophil isolation and assessment of apoptosis. We isolated peripheral blood neutrophils from healthy, human volunteers (Lothian Research Ethics Committee approvals no. 08/S1103/38 or no. 1702/95/4/72) with the use of dextran sedimentation and Percoll gradients as described, ${ }^{6,19}$ and cultured the cells $\left(5 \times 10^{6} / \mathrm{ml}, 37^{\circ} \mathrm{C}\right)$ in IMDM containing $10 \%$ autologous serum. The cells were incubated with reagents as indicated in the figures either in flat-bottomed 24-well plates or in $2 \mathrm{ml}$ Eppendorf tubes in a humidified, $37^{\circ} \mathrm{C}$ incubator at $5 \% \mathrm{CO}_{2}$ or on a shaking, temperature-controlled heat block. We assessed apoptosis by flow cytometry with a Coulter FACSCaliber flow cytometer (Beckman-Coulter, Brea, CA, USA), using annexin-V-conjugated FLUOS (Roche, Welwyn Garden City, UK) in combination with propidium iodide (PI) (Sigma-Aldrich, Dorset, UK) and used light microscopy of Diff Quick stained cytocentrifuged preparations to confirm the presence of morphological changes characteristic of apoptosis. R-roscovitine was obtained from Calbiochem. 5,6-Dichloro-1- $\beta$-D-ribofuranosylbenzimidazole (DRB) and other chemicals were from Sigma-Aldrich unless stated otherwise.

Western blotting. Cells at a concentration of $5 \times 10^{6} / \mathrm{ml}$ per condition were incubated at $37^{\circ} \mathrm{C}$ on a shaking heat block (for times and reagent concentrations see figure legends). Total cells lysates were prepared at $4{ }^{\circ} \mathrm{C}$ as previously described. ${ }^{13,20}$ Neutrophils were pelleted by centrifugation at $3000 \times g$ for $60 \mathrm{~s}$ and re-suspended either in whole-cell lysis buffer as described (Meijer and Raymond ${ }^{14}$, standard lysis) or in $100 \mu \mathrm{l}$ of cytoplasmic lysis buffer (for nuclear/cytoplasmic differential lysis; AEBSF $0.5 \mathrm{mM}$, HEPES $50 \mathrm{mM}, \mathrm{KCl} 50 \mathrm{mM}, \mathrm{MgCl}_{2} 2 \mathrm{mM}$, EDTA $0.1 \mathrm{mM}$, aprotinin $10 \mu \mathrm{g} / \mathrm{ml}$, levamisole $2 \mathrm{mM}$, leupeptin $10 \mu \mathrm{g} / \mathrm{ml}$, sodium orthovanadate $1 \mathrm{mM}$, benzamidine $0.5 \mathrm{mM}, \beta$-glycerophosphate $10 \mathrm{mM}$, pepstatin A $10 \mu \mathrm{g} / \mathrm{ml}$, phenanthroline $1 \mathrm{mM}$, PMSF $1 \mathrm{mM}$ ). Sample was incubated on ice for $10 \mathrm{~min}$ then $10 \mu \mathrm{l}$ of NP-40 was added, briefly vortexed and centrifuged for $10 \mathrm{~min}$ at $4300 \times g$. Supernatant was removed (the cytoplasmic fraction), and the remaining cell pellet was re-suspended in $50 \mu$ l of nuclear lysis buffer (as cytoplasmic plus $\mathrm{NaCl}$ $300 \mathrm{mM}$ and glycerol $10 \%$ ) and placed at $4{ }^{\circ} \mathrm{C}$ plus constant shaking for $20 \mathrm{~min}$ to solubilise nuclear proteins. Samples were then centrifuged at $23100 \times g$ for $10 \mathrm{~min}$ and supernatant was removed (nuclear fraction). Protein concentration of lysates were assessed by BCA protein assay (Thermo Scientific, Cramlington, UK) to ensure equal protein loading and added to an appropriate volume sample buffer before boiling at $95^{\circ} \mathrm{C}$ for $2 \mathrm{~min}$. Lysate were run on $10-12 \%$ precast gels (Thermo Fisher Scientific, Rockford, IL, USA) or on $4 \%$ polyacrylamide gels and transferred onto PVDF (Immobilon-P, Millipore, Herts, UK). Membranes were blocked for $1 \mathrm{~h}$ in $5 \%$ (wt/vol) dried milk/TBS/0.1\% Tween-20 or $5 \%$ BSA TBS $/ 0.1 \%$ Tween-20 (RNAPol II). Membranes incubated at $4{ }^{\circ} \mathrm{C}$ overnight with primary antibodies; Mcl-1 diluted 1:500 (mouse monoclonal from R\&D, Abingdon, UK and rabbit polyclonal from Santa Cruz Biotechnology, Santa Cruz, CA, USA); $\beta$-actin diluted 1:10000 (Sigma-Aldrich); CDK2, 5, 7 and 9 and cyclins T1 and $\mathrm{H}$ diluted 1:500 (Santa Cruz Biotechnology); RNAPol II diluted 1:250 (Covance, Princeton, NJ, USA); GAPDH diluted 1:20000 (Sigma-Aldrich), Histone H3 diluted 1:5000 (Abcam, Cambridge, UK). Following $3 \times 5$ min washes in TBS/0.1\%Tween-20, the blots were incubated with HRP-conjugated secondary antibody (Dako, Glostrup, Denmark) diluted $1: 2500$ for $1 \mathrm{~h}$ at room temperature before incubation with $\mathrm{ECL}$ reagents (GE Healthcare, Bucks, UK) exposure to BioMax MS-1 x-ray-sensitive film, and processing (X-Ograph Imaging Systems, Wilts, UK). Densitometry was carried out using ImageJ software (NIH, Bethesda, MD, USA). Where appropriate HL-60 and HepG2 cell lines were used as positive controls.

Immunofluorescence for neutrophil CDKs 7 and 9 and RNA pol II. Neutrophils at $2.5 \times 10^{6} / \mathrm{ml}$ were incubated with treatments in $2 \mathrm{ml}$ Eppendorf tubes on a $37^{\circ} \mathrm{C}$ shaking heat block for the indicated time-points and pelleted by centrifugation at $300 \times g$ for 4 min before resuspension and transfer to coverslips. They were then fixed for $20 \mathrm{~min}$ in $3 \%$ paraformaldehyde. After washing and quenching with $50 \mathrm{mM}$ glycine, cells were re-suspended in $50 \mu \mathrm{l}$ of $10 \%$ goat serum (as secondary antibodies were goat) and blocked for $1 \mathrm{~h}$. Supernatant was removed and coverslips were gently placed onto $100 \mu \mathrm{l}$ of indicated primary antibody diluted as indicated for $1 \mathrm{~h}$. Following washing, the cells were incubated with $50 \mu \mathrm{l}$ of appropriate fluorescent-conjugated secondary antibody as well as nuclear stain (DAPI/PI, $2 \mu \mathrm{l}$ in $1 \mathrm{ml}$ ) for $1 \mathrm{~h}$ before further 
washing in PBS and finally $\mathrm{ddH}_{2} \mathrm{O}$. All experiments included control slides incubated with no antibody, primary antibody alone or secondary antibody alone. Coverslips were transferred to slides and mounted with mowiol and nail varnish before visualisation on confocal microscope (Leica SP5, Leica Microsystems GmbH, Wetzlar, Germany).

Assessment of mitochondrial integrity. MitoCapture (Biovision, Milpitas, CA, USA) is a fluorescence-based tool for detecting changes in the mitochondrial transmembrane potential. Neutrophils were isolated as above and incubated with appropriate reagent at a concentration of $5 \times 10^{4} / \mathrm{ml}$ in a flat-bottomed 96-well plate at $37^{\circ} \mathrm{C}, 5 \% \mathrm{CO}_{2}$ for $2 \mathrm{~h}$. MitoCapture kit used as per manufacturer's instructions. Fluorescence microscopy was performed using a Zeiss Axiovert S100 (Zeiss, Oberkochen, Germany) microscope. Cells fluorescing green had lost mitochondrial membrane potential, whereas those fluorescing orange/red had intact mitochondria. Three separate experiments with three replicates of individual treatments were performed. Photographs were made and 500 cells were counted per replicate.

RNA isolation. Neutrophil purity was confirmed by flow cytometry before RNA isolation was performed with an initial trizol (Life Technologies, Carlsbad, CA, USA) extraction stage followed by the use of a Nucleospin RNA II kit (MachereyNagel, Duren, Germany) as per manufacturer's instructions. RNA was quantified and assessed with the use of an Agilent Bioanalyser (Santa Clara, CA, USA) before the gene-chip assay was performed.

Illumina Gene Chip assessment of neutrophil transcriptome. This was performed by ARK-genomics (Roslin, Midlothian, Scotland, UK) and subsequent bioinformatics data was generated by Dr. Jon Manning, CIR Bioinformatics division. Data output by the proprietary Illumina software were handled using modules of the R-based Bioconductor software suite (http:// www.bioconductor.org). Version 1.14 .0 of the 'lumi' package formed the core of the analysis, providing the routines employed to read, adjust background intensity, transform and normalise the data. The 'variance stabilising transform' suggested by this module's authors was employed in place of the more conventional logtransform, before robust spline normalisation. Annotation data were derived initially from an Illumina-provided annotation file, with complementary information taken from the chip-specific 'illuminaHumanv3' and more generic 'lumiHumanAll' Bioconductor annotation packages. The level and significance of differential expression for each probe was assessed by use of linear models and empirical Bayes from the 'Limma' package and the resulting $P$ values were adjusted for multiple testing by use of the Benjamini-Hochberg method. Fold changes were derived with the aid the 'gtools' package. Processed data were stored in a relational database with a dynamic front-end for further analysis. ${ }^{21-23}$

\section{Administration of bleomycin sulphate and CDK inhibitor drugs.} Female C57BL/6J mice weighing a minimum of $20 \mathrm{~g}$ were used for all experiments. The mice were briefly anesthetised using Isofluorane and bleomycin sulphate $(0.033 \mathrm{mg}$; Apollo Scientific, Cheshire, UK) administered to the lungs via the trachea (i.t.), in a volume of $50 \mu \mathrm{l}$. On day 2 and 5 post-bleomycin administration, mice (6 per group) were treated i.t. with either $50 \mu \mathrm{l}$ of $0.05 \%$ DMSO vehicle control or $10 \mathrm{mg} / \mathrm{kg}$ of R-roscovitine or DRB.

BAL and histology. Mice were killed 7 days after bleomycin or saline administration with a single $200 \mu$ lintraperitoneal injection of sodium pentobarbitone $(200 \mathrm{mg} / \mathrm{ml})$. The lungs were cannulated via the trachea in situ using a fine cannula that was tied in place with a single suture and BAL was performed using three sequential washes of $0.8 \mathrm{ml}$ ice-cold sterile $0.9 \%$ saline. All samples were centrifuged at $180 \mathrm{~g}$ for $5 \mathrm{~min}$ at $4{ }^{\circ} \mathrm{C}$, the supernatants removed and the cell pellets resuspended in $0.5 \mathrm{ml}$ sterile $0.9 \%$ saline. Total cell numbers were counted using a nucleocounter and cytocentrifuge smears prepared and stained with Diff Quick for differential cell-counts to be made. At least 300 cells per slide were counted and the results expressed as total number of neutrophils and macrophages in the lung lavage. Histological analysis of the 7 day experiments (3 mice per group) was undertaken without BAL to maintain tissue integrity and lung injury was assessed by histological examination of paraffin-embedded lung sections stained with hematoxylin and eosin.

Statistical analyses (excluding illumina data, see above). All experiments were performed at least three times unless stated otherwise and each treatment done in triplicate and the results are expressed as the mean \pm S.E.M.
Data were analysed by an one-way ANOVA with a Student's Newman-Keuls multiple comparison post hoc test with a 95\% confidence interval (InStat software, Graphpad Software Inc., La Jolla, CA, USA).

\section{Conflict of Interest}

The authors declare no conflict of intrest.

Acknowledgements. We thank Dr. Donald Dunbar and Dr. Jonathon Manning of the CIR Bioinformatics division for processing of microarray data. Dr. David A Dorward for assistance with the generation of samples for western blotting. This work was funded by MRC Grant (G0601481) and Wellcome Trust Grants (WT082181, WT094415).

1. Geering B, Simon HU. Peculiarities of cell death mechanisms in neutrophils. Cell Death Differ 2011; 18: 1457-1469.

2. Savill JS, Wyllie AH, Henson JE, Walport MJ, Henson PM, Haslett C. Macrophage phagocytosis of aging neutrophils in inflammation. Programmed cell death in the neutrophil leads to its recognition by macrophages. J Clin Invest 1989; 83: 865-875.

3. Lee A, Whyte MK, Haslett C. Inhibition of apoptosis and prolongation of neutrophil functional longevity by inflammatory mediators. J Leukoc Biol 1993; 54: 283-288.

4. Whyte MK, Meagher LC, MacDermot J, Haslett C. Impairment of function in aging neutrophils is associated with apoptosis. J Immunol 1993; 150: 5124-5134.

5. Ren Y, Xie Y, Jiang G, Fan J, Yeung J, Li W et al. Apoptotic cells protect mice against lipopolysaccharide-induced shock. J Immunol 2008; 180: 4978-4985.

6. Rossi AG, Sawatzky DA, Walker A, Ward C, Sheldrake TA, Riley NA et al. Cyclindependent kinase inhibitors enhance the resolution of inflammation by promoting inflammatory cell apoptosis. Nat Med 2006; 12: 1056-1064.

7. McGrath EE, Marriott HM, Lawrie A, Francis SE, Sabroe I, Renshaw SA et al. TNF-related apoptosis-inducing ligand (TRAIL) regulates inflammatory neutrophil apoptosis and enhances resolution of inflammation. J Leukoc Biol 2011; 90: 855-865.

8. El KD, Jozsef L, Pan W, Wang L, Petasis NA, Serhan CN et al. 15-epi-lipoxin A4 inhibits myeloperoxidase signaling and enhances resolution of acute lung injury. Am J Respir Crit Care Med 2009; 180: 311-319.

9. Leuenroth SJ, Grutkoski PS, Ayala A, Simms HH. The loss of Mcl-1 expression in human polymorphonuclear leukocytes promotes apoptosis. J Leukoc Biol 2000; 68: 158-166.

10. Dzhagalov I, St JA, He YW. The antiapoptotic protein Mcl-1 is essential for the survival of neutrophils but not macrophages. Blood 2007; 109: 1620-1626.

11. Edwards SW, Derouet M, Howse M, Moots RJ. Regulation of neutrophil apoptosis by Mcl-1. Biochem Soc Trans 2004; 32: 489-492.

12. Andina N, Conus S, Schneider EM, Fey MF, Simon HU. Induction of Bim limits cytokinemediated prolonged survival of neutrophils. Cell Death Differ 2009; 16: 1248-1255.

13. Leitch AE, Riley NA, Sheldrake TA, Festa M, Fox S, Duffin R et al. The cyclin-dependent kinase inhibitor R-roscovitine down-regulates $\mathrm{Mcl}-1$ to override pro-inflammatory signalling and drive neutrophil apoptosis. Eur J Immunol 2010; 40: 1127-1138.

14. Meijer L, Raymond E. Roscovitine and other purines as kinase inhibitors. From starfish oocytes to clinical trials. Acc Chem Res 2003; 36: 417-425.

15. Knockaert M, Greengard P, Meijer L. Pharmacological inhibitors of cyclin-dependent kinases. Trends Pharmacol Sci 2002; 23: 417-425.

16. MacCallum DE, Melville J, Frame S, Watt K, Anderson S, Gianella-Borradori A et al. Seliciclib (CYC202, R-Roscovitine) induces cell death in multiple myeloma cells by inhibition of RNA polymerase II-dependent transcription and down-regulation of Mcl-1. Cancer Res 2005; 65: 5399-5407.

17. McDonald PP, Bovolenta C, Cassatella MA. Activation of distinct transcription factors in neutrophils by bacterial LPS, interferon-gamma, and GM-CSF and the necessity to overcome the action of endogenous proteases. Biochemistry 1998; 37: 13165-13173.

18. Cassatella MA, Gasperini S, Calzetti F, McDonald PP, Trinchieri G. Lipopolysaccharideinduced interleukin-8 gene expression in human granulocytes: transcriptional inhibition by interferon-gamma. Biochem J 1995; 310: 751-755.

19. Haslett C, Guthrie LA, Kopaniak MM, Johnston RB Jr., Henson PM. Modulation of multiple neutrophil functions by preparative methods or trace concentrations of bacterial lipopolysaccharide. Am J Pathol 1985; 119: 101-110.

20. Marwick JA, Caramori G, Stevenson CS, Casolari P, Jazrawi E, Barnes PJ, Ito K, Adcock IM, Kirkham PA, Papi A. Inhibition of PI3Kdelta restores glucocorticoid function in smokinginduced airway inflammation in mice. Am J Respir Crit Care Med 2009; 179: 542-548.

21. Du P, Kibbe WA, Lin SM. lumi: a pipeline for processing Illumina microarray. Bioinformatics 2008; 24: 1547-1548.

22. Hochberg Y, Benjamini Y. More powerful procedures for multiple significance testing. Stat Med 1990; 9: 811-818.

23. Hochberg $Y$, Benjamini $Y$. Controlling the false discovery rate: A practical and powerful approach to multiple testing. J.R.Statist.Soc 1995; 57: 289-300.

24. Whyte MK, Savill J, Meagher LC, Lee A, Haslett C. Coupling of neutrophil apoptosis to recognition by macrophages: coordinated acceleration by protein synthesis inhibitors. J Leukoc Biol 1997; 62: 195-202. 
25. Ward C, Chilvers ER, Lawson MF, Pryde JG, Fujihara S, Farrow SN et al. NF-kappaB activation is a critical regulator of human granulocyte apoptosis in vitro. J Biol Chem 1999; 274: $4309-4318$.

26. Cassatella MA. The production of cytokines by polymorphonuclear neutrophils. Immuno Today 1995; 16: 21-26.

27. Wang $P$, Wu P, Anthes JC, Siegel MI, Egan RW, Billah MM. Interleukin-10 inhibits interleukin-8 production in human neutrophils. Blood 1994; 83: 2678-2683.

28. Geering B, Schmidt-Mende J, Federzoni E, Stoeckle C, Simon HU. Protein overexpression following lentiviral infection of primary mature neutrophils is due to pseudotransduction. J Immunol Methods 2011; 373: 209-218.

29. Maas Jr JW, Horstmann S, Borasio GD, Anneser JM, Shooter EM, Kahle PJ. Apoptosis of central and peripheral neurons can be prevented with cyclindependent kinase/mitogen-activated protein kinase inhibitors. J Neurochem 1998; 70: $1401-1410$.

30. Klausen P, Bjerregaard MD, Borregaard N, Cowland JB. End-stage differentiation of neutrophil granulocytes in vivo is accompanied by up-regulation of p27kip1 and down-regulation of CDK2, CDK4, and CDK6. J Leukoc Biol 2004; 75: 569-578.

31. Scatizzi JC, Mavers M, Hutcheson J, Young B, Shi B, Pope RM et al. The CDK domain of p21 is a suppressor of IL-1beta-mediated inflammation in activated macrophages. Eur $\mathrm{J}$ Immunol 2009; 39: 820-825.

32. Lloberas J, Celada A. p21(waf1/CIP1), a CDK inhibitor and a negative feedback system that controls macrophage activation. Eur J Immunol 2009; 39 691-694.
33. Zhu Y, Pe'ery T, Peng J, Ramanathan $Y$, Marshall N, Marshall $T$ et al. Transcription elongation factor P-TEFb is required for HIV-1 tat transactivation in vitro. Genes Dev 1997; 11: 2622-2632.

34. Roy R, Adamczewski JP, Seroz T, Vermeulen W, Tassan JP, Schaeffer L et al. The M015 cell cycle kinase is associated with the TFIIH transcription-DNA repair factor. Cell 1994; 79 : 1093-1101.

35. Nowak DE, Tian B, Jamaluddin M, Boldogh I, Vergara LA, Choudhary S et al. RelA Ser276 phosphorylation is required for activation of a subset of NF-kappaB-dependent genes by recruiting cyclin-dependent kinase 9/cyclin T1 complexes. Mol Cell Biol 2008; 28: 3623-3638.

36. Barboric M, Nissen RM, Kanazawa S, Jabrane-Ferrat N, Peterlin BM. NF-kappaB binds P-TEFb to stimulate transcriptional elongation by RNA polymerase II. Mol Cell 2001; 8: 327-337.

37. Bouillet P, Metcalf D, Huang DC, Tarlinton DM, Kay TW, Kontgen F et al. Proapoptotic $\mathrm{Bcl}-2$ relative Bim required for certain apoptotic responses, leukocyte homeostasis, and to preclude autoimmunity. Science 1999; 286: 1735-1738.

38. Cowburn AS, Summers C, Dunmore BJ, Farahi N, Hayhoe RP, Print CG et al. GM-CSF causes a Paradoxical Increase in the BH3-only Pro-Apoptotic Protein BIM in Human Neutrophils. Am J Respir Cell Mol Biol 2011; 44: 879-887.

$$
\text { (c) }
$$

This work is licensed under the Creative Commons Attribution-NonCommercial-No Derivative Works 3.0 Unported License. To view a copy of this license, visit http://creativecommons.org/licenses/by-nc-nd/3.0 